\title{
Diurnal patterns of volatile organic compounds in the atmosphere of Sao Jose dos Campos
}

Ana Paula dos Santos Zepka, Kelly Ribeiro, Willian José Ferreira, Plínio Carlos Alvalá (CCST-DGE-INPE)

Copyright 2011, SBGf - Sociedade Brasileira de Geofísica

This paper was prepared for presentation during the $12^{\text {th }}$ International Congress of the Brazilian Geophysical Society held in Rio de Janeiro, Brazil, August 15-18, 2011.

Contents of this paper were reviewed by the Technical Committee of the $12^{\text {th }}$ International Congress of the Brazilian Geophysical Society and do not necessarily represent any position of the SBGf, its officers or members. Electronic reproduction or storage of any part of this paper for commercial purposes without the written consent of the Brazilian Geophysical Society is prohibited.

\section{Abstract}

The study of the concentration of volatile organic compounds in the atmosphere is of fundamental importance because it contributes to environmental pollution like photochemical smog as well as its toxic effects on health. The city of Sao Jose dos Campos, Sao Paulo, Brazil, in recent years has shown strong growth and increasing in the industrial economy, leading to an intense development of the urban area. In addition, the city is geographically located near the capital Sao Paulo, Brazil, and is surrounded by roads that have heavy flow of vehicles, which characterizes this region as potential for the emission of VOCs. This paper aims to characterize the daily cicle of emission of light VOCs $\left(\mathrm{C}_{1}-\mathrm{C}_{6}\right)$ in Sao Jose dos Campos, being collected and analyzed air samples from Univap region $7.5 \mathrm{~km}$ from the city center, away from roads and main avenues, located in the neighborhood Urbanova.

The most abundant organic species found were: $n$ butane, n-pentane, 1-butene, trans-2-butene, cis-2butene, 1-pentene and isoprene.

\section{Introduction}

The nomenclature used by Derwent (1995) and also considered in this work is that the term VOCs (volatile organic compound) as any compound containing carbon that reacts photochemically in the atmosphere, excluding elemental carbon, carbon monoxide and carbon dioxide. They are called organic because they contain carbon in atom and in the urban centers contribute to the formation of tropospheric ozone. In the presence of ultraviolet radiation $(\lambda \leq 335 \mathrm{~nm})$ and oxides of nitrogen (NOx) act in the formation of photochemical oxidants, characterizing the process known as photochemical smog (Figure 1).

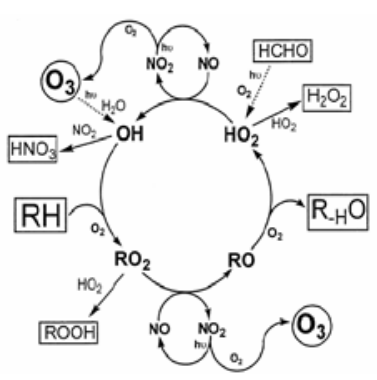

Fig. 1- Mechanism of formation of photochemical smog. Jenkin and Chemitshaw (2000).

The emission of VOCs occurs both anthropogenic and biogenic sources and contribute to increased air pollution but also cause toxic effects in human and animal health. Studies show that high concentrations of gases in the atmosphere are directly correlated with mortality.

Sao Jose dos Campos, Sao Paulo, Brazil is a city that has shown great industrial development and intensive growth of the urban area. The city is located near the capital Sao Paulo and therefore characterized as a region for the potential emission of VOCs.

While in Brazil the adverse consequences of VOCs are known, there is no regulation to control their emissions. Studies that monitoring these compounds contribute to the development of programs to control air pollution in large urban centers.

The objective of this work is to characterize the daily cicle of emission of light VOCs $\left(\mathrm{C}_{1}-\mathrm{C}_{6}\right)$ in Sao Jose dos Campos.

\section{Method}

The methodology for sampling of VOCs used in this study was based on the method 17 of the U.S. Environmental Protection Agency (EPA, 1999) which consists of the collection in tubes followed by adsorption preconcentration by thermal dessorption (Dessorption TurboMatrix ATD150 Perkin Elmer) and analyzed by gas chromatography with FID detector and two columns, a methyl silicone as pre-analysis and RT-Alumina PLOT specific to compounds $\mathrm{C}_{1}-\mathrm{C}_{6}$. This technique allows to measure very small concentrations, the trace level of a variety of compounds in the environment.

The sampling was performed in the Univap, Urbanova district $\left(23^{0} 12.5^{\prime} \mathrm{S}, 45^{0} 57.2^{\prime} \mathrm{W}\right)$, remote area about $7.5 \mathrm{~km}$ from the city center. 
Samples were collected on June 17, 2010, every hour through a portable air pump coupled to denuders adsorbents Perkin Elmer type air toxics.

The quantification of chemical compounds by calculating the response factor (RFi) for each compound is relative to a reference compound (Ackman, 1964). In this work was used as reference compound isoprene, with mixing ratio $84 \mathrm{ppbv}$ in the standard gas. The response factor for isoprene (RFn) was determined according to the equation:

$$
R F n=[\text { isoprene }] /[\text { peakarea }]
$$

Relative response factors (RRFi) was calculated for each compound using the equation (Goldstein et al., 1995):

$$
\begin{gathered}
R R F i=(\operatorname{mass} \% C i)(\# C i) /(\operatorname{mass} \% C n)(\# C n), \text { where: } \\
\text { mass } \% C=100 \%(\# C i)(12.01) /(\# C i)(12.01)+(\# H i)(1.008) \text {, where: }
\end{gathered}
$$

$\# \mathrm{C}$ and $\# \mathrm{H}$ refer to the number of carbon and hydrogen atoms in the molecule, respectively. Then:

$$
R F i=R F n / R R F i
$$

RFi multiplied by the peak area yields concentration values for the individual compounds.

Tab. 1 - VOCs found to be separable, identifiable, and quantifiable on the RT-Alumina PLOT column

\begin{tabular}{cccc}
\hline Compound & RRFi & RFp & RFi \\
\hline n-butane & 0,75 & 0,80 & 1,07 \\
1-butene & 0,78 & 0,80 & 1,03 \\
trans-2-butene & 0,78 & 0,80 & 1,03 \\
cis-2-butene & 0,78 & 0,80 & 1,03 \\
n-pentane & 0,94 & 0,80 & 0,85 \\
1-pentene & 0,97 & 0,80 & 0,82 \\
isoprene & 1 & 0,80 & 0,80 \\
\hline
\end{tabular}

Where RRFi denotes weighted response factor for the individual compound relative to isoprene; RFp denotes response factor for isoprene, the standard gas; RFi is the relation between concentration $(\mathrm{ppb})$ and peak area unit.

Were also collected meteorological parameters such as temperature, solar radiation, wind and ozone measurements from a meteorological station located in Univap.

\section{Results}

According Lamanna \& Goldstein (1999) measured VOCs are categorized into groups based on factor analysis of the full VOC data and separated based on their source of emission and environmental parameters.

The factor analysis differentiated compounds which were solely anthropogenically emitted (factor 1 ), solely biogenically emitted (factor 2), temperature dependent biogenic emissions (factor 3 ) temperature and light dependent biogenic emissions (factor 6 ) or emitted from a combination of anthropogenic sources plus light dependent biogenic emissions (factor 4) and anthropogenic sources plus biogenic emissions (factor 5 ).
These factors names were prescribed based on previous knowledge of sources and the observed temporal patterns for the primary compounds.

The most abundant organic species found in descending order of concentration in the study area were: n-butane, n-pentane, 1-butene, trans-2-butene, cis-2-butene, 1pentene and isoprene.

In general, the compounds were grouped in factor 1 , as nbutane and n-pentane, and other compounds identified as factor 4 , treating isoprene, factor 6 , as an isolated case.

The results show the variation of concentrations of hydrocarbons throughout the day by following a standard cycle. The values reached their maximum at two different times of day, the next 12 hours and between 16 and 20 hours, concentrations directly related to increased traffic, light vehicles, while the inputs and outputs of the university during peak hours.

Fig. 2 - Concentration of n-butane and n-pentane ( $p p b)$ collected at Univap on June 17, 2010.

Butane decreased to its lowest concentration in the morning.

Fig. 3 - Concentration of 1-butene, trans-2-butene, cis-2butene and 1-pentene (ppb) collected at Univap on June $17,2010$. 
The isoprene was the VOC whose photochemistry behaved typically as biogenic emissions, not suffering any apparent influence of local pollution and anthropogenic emission.

It would be interesting to a longer period of data collection in order to understand its importance to regional photochemistry.

\section{Acknowledgment}

Cnpq for a PhD scholarship from the first author.

Fig. 4 - Concentration of isoprene ( $p p b)$ collected at Univap on June 17, 2010.

Isoprene (factor 6) had clear diurnal cycles with maximum concentrations in the afternoon and minimum concentrations in the early morning.

In the early morning, local biogenic emissions would be most apparent because the vertical mixing rates were low and anthropogenic emissions are still less intense.

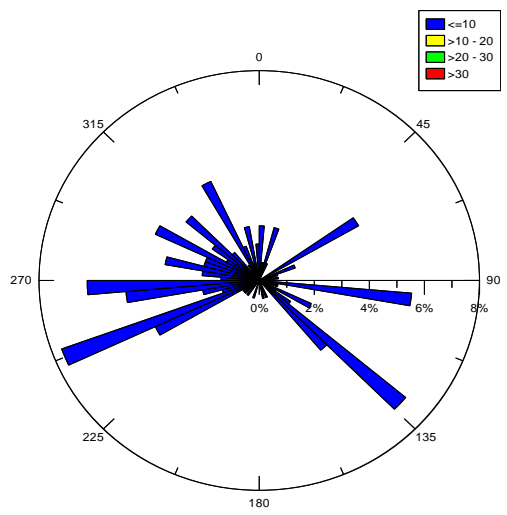

Fig. 5 - Behavior of the trajectory of air masses during the day June 17, 2010.

Observed this day of collection recorded low-intensity

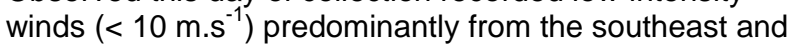
southwest of the city (Figure 5). The concentration of the gases was local contribution only, since the wind speed did not contribute to the drag occurred.

\section{Conclusions}

On June 17, 2010 was accompanied the daily cycle of emission of VOCs in the region of Univap. Through the sampling of chemical by denuders was possible to detect elements in parts per billion (ppb).

Local measures have the objective to know the location of the possible sources gas. Because the wind speed in the region is low, it is believed that the transport processes of air masses do not act in the region considering thus a stationary case.

\section{References}

Ackman, R.G., 1964. Fundamental groups in the response of flame ionization detectors to oxygenated aliphatic hydrocarbons. J. Gas Chromatogr., 2, 173-179.

Derwent, R.G., 1995. Air chemistry and terrestrial gas emissions: A global perspective. Philos. Trans. R. Soc. London, Ser. A, 351, 205-217.

EPA - Environmental Protection Agency, 1999. METHOD TO-17, Determination of Volatile Organic Compounds in Ambient Air Using Active Sampling Onto Sorbent Tubes.

Goldstein, A.H., Daube, B.C., Munger, J.W. \& Wofsy, S.C., 1995. Automated in-situ monitoring of atmospheric non-methane hydrocarbon concentrations and gradients. J. Atmos. Chem., 21, 43-59.

Jenkin, M.E. \& K.C. Clemitshaw, 2000. Ozone and other secondary photochemical pollutants: chemical processes governing their formation in the planetary boundary layer. Atm. Environ., 34, 2499-2527.

Lamanna, M.S, \& A.H. Goldstein, 1999. In situ measurements of C2-C10 volatile organic compounds above a Sierra Nevada ponderosa pine plantation. Journal of Geophysical Research, 104, 21247-21262. 